\title{
PEMBINAAN ANCAMAN HUKUMAN PENYALAHGUNAAN NARKOTIKA DI MADRASAH ALIYAH DARUL IHSAN TANJUNG SENGKUANG KOTA BATAM
}

\author{
Zuhdi Arman \\ Universitas Putera Batam (UPB), Batam, Indonesia \\ Zuhdi@puterabatam.ac.id \\ Michael Jibrael Rorong \\ Universitas Putera Batam (UPB) Batam, Indoensia. \\ Michael.rorong@puterabatam.ac.id \\ Irene Svinarky \\ Universitas Putera Batam (UPB), Batam, Indonesia \\ irene@puterabatam.ac.id
}

\begin{abstract}
The purpose of this PKM is to provide guidance to students and school students in order to understand the rules on Narcotics, so as not to misreact against the misuse of narcotics. The target of this PKm is students from Madrasah Aliyah Darul Ihsan School Tanjung Sengkuang Batam City, the methods used in this devotion are: First, this method of education is expected to have a function so that the problems among adolescents regarding narcotic abuse decrease by giving an idea of the rules governing narcotics; Second, the method of coaching understanding related to the threat of punishment from drug abuse Details of the solutions offered. In this devotion the team did not produce the product, but rather led to an improved education on the misuse of Narcotics, which made a bad impact for its users.
\end{abstract}

Keywords- Sanctions, Narcotics, Unauthorized

\section{PENDAHULUAN}

Di zaman serba canggih seperti saat sekarang ini sangat mudah sekali melihat dimedia sosial mengenai penyalahgunaan narkotika. Undang-undang mengenai Narkotika itu sendiri telah di atur di dalam Undang-Undang Nomor 35 Tahun 2009 tentang Narkotika (BNN, 2019), yang mana undang-undang ini dapat disingkat dengan

UU

Narkotika (https://www.hukumonline.com/pusatdata/detail/lt4af3b7f6cf607/nprt/1060/uu-no35-tahun-2009-narkotika, 2009). Selain UU Narkotika juga diatur turunan peraturannya di dalam Permenkes Nomor 7 Tahun 2018 tentang Perubahan Penggolongan Narkotika. Semua orang tahu apa itu narkoba namun tidak banyak orang yang mengetahui narkoba merupakan singkatan dari narkotika dan obatobatan, tetapi masih banyak yang kurang memahami apa itu narkotika. Pengertian 
Narkotika itu sendiri terdapat dalam Pasal 1 ayat (1). Untuk lebih mengetahui mengenai Narkotika maka harus memahami aturan yang berlaku di dalam UU Narkotika. Di dalam UU Narkotika yang dimaksud dengan Narkotika terdiri dari 3 golongan. Adapun golongan dari Narkotika adalah Golongan I; Golongan II dan Golongan III yang terdapat di (Pasal 6). Narkotika itu dapat digunakan untuk pelayanan kesehatan dan untuk dapat mengembangkan ilmu pengetahuan dan teknologi yang terdapat di (Pasal 7). Namun Narkotika itu tidak dapat dijual, didistribusikan sembarangan. Untuk menyebarluaskan narkotika harus seizin Menteri Kesehatan dan pendistribusiannya telah sangat jelas diatur di dalam UU Narkotika. Selain itu bagi perusahaan yang ingin mengekspor narkotika tersebut harus mendapatkan izin dan memenuhi persyaratan yang harus dipenuhi dari pihak-pihak yang telah ditentukan dalam UU Narkotika.

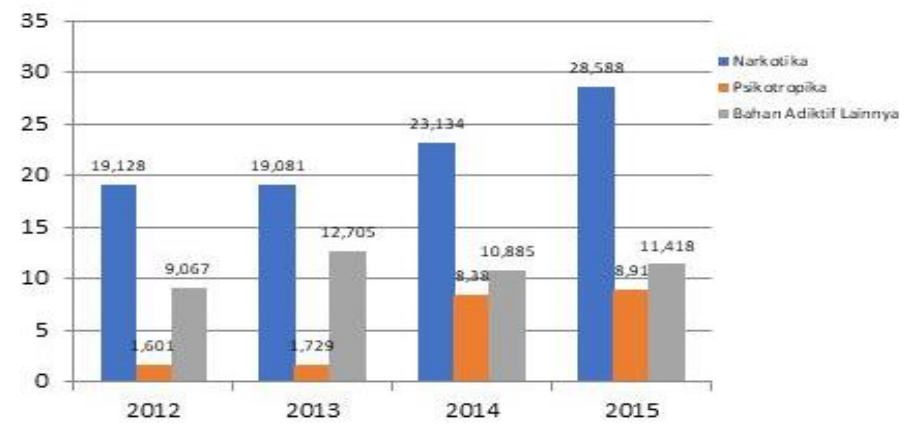

Gambar 1. Grafik Jumlah Kasus Narkoba di Indonesia Sumber: Badan Narkotika Nasional Tahun 2018

Di Indonesia sendiri penyebaran narkoba telah menjadi "Darurat Narkoba" dan harus dicarikan jalan penyelesaiannya dengan segera. Sangat banyak kasus yang telah ditimbulkan oleh narkoba baik materi maupun non materi serta kerugian yang sangat besar setiap tahunnya bagi Indonesia. Penyebaran narkoba di Indonesia yang setiap tahunnya semakin meningkat dipengaruhi oleh jumlah populasi penduduk Indonesia yang besar mencapai 267 juta jiwa pada tahun 2019.

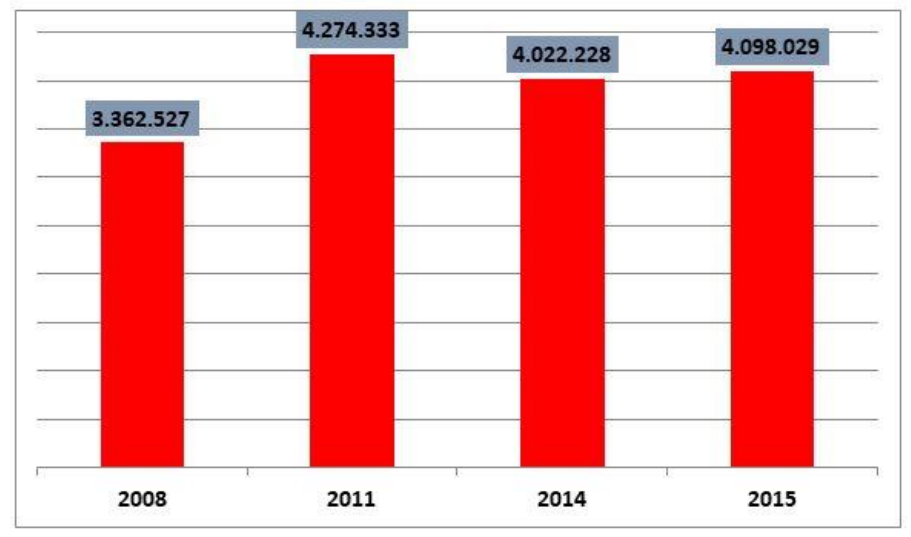

Gambar 2. Grafik Jumlah Penyalahgunaan Narkoba di Indonesia Sumber: bappenas.co.id Tahun 2018 
Di dalam sumber Gambar 2 di atas, tahun 2011 pemakaian narkoba mengalami kenaikan di Indonesia, hal ini dapat terlihat dari website bappenas.co.id di tahun 2018, Website bapenas merupakan website yang digunakan untuk memberikan informasi mengenai hal-hal yang berkaitan dengan narkotika.

Pengabdian yang dilakukan oleh tim pengabdi di Sekolah Madrasah Aliyah Darul Ihsan Tanjung Sengkuang Kota Batam, ditujukan untuk melakukan pembinaan sejak awal memperkenalkan bahaya dari ancaman terhadap penyalahgunaan narkotika. Anak bangsa dapat dirusak secara kesehatan fisik dan juga dalam bidang ekonomi, kesehatan sosial dan keamanan (Kementerian PPN/Bapenas, 2016). Pengetahuan yang diberikan ini dapat memberikan informasi mengenai Ancaman Nerkotika apabila dikosumsi oleh siswa dan siswi dari sekolah Madrasah yang diberikan pengabdian ini. Selain itu antara siswa dan siswi yang masih sekolah harus diberikan pemahaman mengenai UU Narkotika dan hal-hal yang mengakibatkan seseorang dapat dihukum penjara ataupun di hukum mati akibat penyalahgunaan Narkotika. Pada saat observasi ke Madrasah ini, tim pengabdi menyadari bahwa masih kurangnya pemahaman dari siswa dan siswi mengenai penyalahgunaan Narkotika. Mereka masih kurang mengerti mengenai golongan dari Narkotika.

Permasalahan yang ada di sekolah Madrasah yang telah disampaikan di atas untuk saat ini belum ada dari pihak sekolah yang pernah mendapati siswa dan siswinya baik itu membawa, mengkosumsi ataupun mengedarkan narkotika ataupun pihak sekolah belum pernah menangkapan dari siswa-siswinya untuk melakukan penyalahgunaan narkotika. Pengenalan serta pembinaan yang dilakukan oleh Tim Pengabdi terhadap gambaran mengenai Narkotika secara hukum yang mengatur hal tersebut di negara Indonesia maka setiap warga mesyarakat apabila pemerintah pengeluarkan aturan tersebut seharusnya dipatuhi terkecuali ada perubahan atau pergantian dalam aturan yang dilakukan oleh pemerintah yang memiliki kewenangan untuk itu.

Responden yang penulis tuju disini adalah siswa dan siswi dari sekolah Madrasah Aliyah Darul Ihsan Tanjung Sengkuang Kota Batam yang berjumlah: 30 siswa dimana siswanya rata-rata sudah mengenal rokok. Di Aceh sebalum daun ganja di larang untuk ditanam ganja kering dihisap dan dibakar seperti rokok, selain itu juga dapat menggunakan tabung untuk alat menghisapnya, yang tabungnya disebut bong (Admin Umum Sekda, 2019).

Menurut Tim Pengabdi pengenalan mengenai Narkotika sejak dini harus dipahami agar tidak salah terhadap pendidikan yang mengajarkan stop narkoba, karena selama ini masih banyak masyarakat yang hanya mengatakan narkotika itu barang haram namun pada dasarnya masyarakat harus mengetahui kapan narkotika itu dikatagorikan barang haram dan kapan narkotika tersebut dapat digunakan berdasarkan izin dari pemerintah dan dosisnya tidak melebihi batas yang ditentukan. Berikut ini adalah situasi saat Tim pengabdi memberikan pembinaan kepada siswa dan siswi madrasah, dengan memberikan gambaran mengenai narkotika yang disalahgunakan pemakaiannya oleh pihak yang tidak memiliki izin sehingga membentuk zat baru atau faktor kecanduan dan apabila dosisnya tidak sesuai maka akan menimbulkan kematian. 
Adapun jenis-jenis dari narkotika antara lain:

1. Morfin, nama lainnya adalah Morpheus (dewa mimpi). Ditemukan pada opium zat alkaloid analgesik, yaitu zat yang mempengaruhi sistem saraf untuk menghilangkan rasa sakit (BNN, 2019).

2. Heroin merupakan hasil dari pengolahan kimiawi, dimana reaksi yang lebih kuat dari pada morfin, sehingga otak sangat mudah ditembus oleh obat tersebut (BNN, 2019).

3. Ganja merupakan tumbuhan yang ada bijinya, dimana bijinya tersebut yang membuat si pemakai menjadi euforia (BNN, 2019)

Untuk meningkatkan pemahaman siswa dan siswi mengenai narkotika dan penyalahgunaannya sehingga mendapatkan hukuman, maka tipengabdi memiliki tujuan pengabdian sebagai berikut:

1. Dapat mengupayakan pemberian pemebinaan kepada siswa dan siswi Madrasah Aliya Darul Ihsan terkait bahaya narkoba bagi genarasi muda

2. Memberikan gambaran mengenai penyalahgunaan narkoba dan ancaman hukumannya.

\section{METODE}

Pertama adalah Metode pendidikan ini diharapkan memiliki fungsi agar permasalahan dikalangan remaja mengenai penyalahgunaan narkotika semakin menurun dengan memberikan gambaran mengenai aturan yang mengatur mengenai narkotika sejak mulai di bangku sekolah. Selama ini mengenai narkotika masih banyak yang menyalahpahami sehingga dalam pikiran masyarakat narkotika tersebut adalah benda haram. Namun sebenarnya sebelum mengatakan narkotika benda haram, terlebih dahulu harus mengetahui narkotika ini digunakan untuk apa, dan manfaatnya bagaimana, kerugiannya seperti apa apabila dikosumsi dari pihak yang tidak memiliki izin dari pemerintah. Hal ini memang perlu dijelaskan karena izin yang diberikanpun oleh pemerintah bukan sekedar izin saja tetapi melakukan banyak test dan step-step uji coba produk agar izin tersebut dapat keluar dan dapat beredar di masyarakat. Pembinaan pemahaman tentang bahaya narkoba.

Kedua Metode Pembinaan pemahaman terkait ancaman hukuman dari penyalahgunaan narkoba Rincian dari solusi yang ditawarkan Tim Pengabdi kepada siswa dan siswi Madrasah Aliyah Darul Ihsan Tanjung Sengkuang Batam sebagai berikut:

1. Dari sudut komunikasi pola komunikasi yang disampaikan oleh para penyuluh narkotika seharusnya lebih memberikan edukasi, ketika terjadi penangkapan yang dilakukan oleh pihak yang memiliki kewenangan untuk itu karena selama ini narkotika selalu yang tergambar negatif namun tidak diberikan gambaran mengenai aturannya yang berlaku di Indonesia.

2. Dari sudut pandang hukum, pembinaan yang dilakukan Tim Pengabdi disini mengajarkan sesuai bidang keilmuan hukum, mengenai narkotika yang ada dibahas salam UU Narkotika sehingga untuk lebih jelasnya siswa dan siswi dapat melakukan magang di BNN atau BPOM apabila berminat mengetahui lebih rinci mengenai Narkotika dan melihat langsung penanganan rehabilitasi dari pecandu narkotika di BNN jika diizinkan oleh pihak BNN. 
Waktu Dan Pelaksanaan Pembinaan Tentang Penyalahgunaan Narkotika Dan Ancaman Hukuman di Madrasah Aliyah Darul Ihsan Tanjung Sengkuang Batam dilaksanakan pada Bulan Januari sampai Desember 2019 selama 2 (dua) kali pertemuan, hari pertama dari jam 09.00-11.30. Pertemuan kedua dari jam 09.00 - 11.30 sedangkan pertemuan ketiga dari jam 09.00-11.30. Pertemuan ke empat dari jam 09.00-11.30, Pertemuan kelima dari jam 09.00-11.30, Pertemuan ke enam dari jam 09.00-11.30. Tempat pelaksanaan di Madrasah Aliyah Darul Ihsan Tanjung Sengkuang Batam, yang diikuti Siswa/Siswi kelas X-XII.

Metode Pelaksanaan kegiatan yang dilakukan dalam pengabdian ini adalah sebagai berikut:

Tabel 1. Metode Pelaksanaan

\begin{tabular}{|c|l|c|c|}
\hline No & \multicolumn{1}{|c|}{ Pertemuan } & Materi yang disampaikan & Pemateri \\
\hline 1. & $\begin{array}{l}\text { Pertemuan } \\
\text { Pertama }\end{array}$ & Pengetahuan tentang narkoba & Ketua \\
\hline 2. & $\begin{array}{l}\text { Pertemuan } \\
\text { Kedua }\end{array}$ & Pembinaan kesadaran hukum & Ketua \\
\hline
\end{tabular}

Untuk evaluasi secara umum, Tim Pengabdi yang sudah melaksanakan kegiatan dipertemuan akhir akan diberikan bebapa pertanyaan berupa objektif mengenai narkotika yang telah dilaksanakan pembinaan selama dua pertemuan dengan tujuan untuk mengukur sejauh mana peserta memahami materi tentang penyalahgunaan narkoba. Pada kegiatan pengabdian ini untuk tim pengusul akan melihat beberapa hasil dan target capaian yang disesuaikan dengan tujuan dari kegiatan pembinaan kepada masyarakat ini adalah:

1. Motivasi. Peserta dalam pengabdian ini terutama bagi siswa dan siswi terkait bahaya narkoba bagi generasi muda dan ancaman hukumannya.

2. Fasilitas yang disediakan oleh Pengabdi dirasa sangat baik oleh peserta berupa konsumsi.

\section{HASIL DAN PEMBAHASAN}

1. Upaya yang dilakukan oleh Tim Pengabdi dalam pengabdian ini

Hasil pengabdian yang tim pengabdi dapatkan dalam pengabdian ini adalah Siswa dan siswi dari sekolah madrasah ini sudah mulai memahami mengenai pembinaan berdasarkan pendidikan terhadap narkotika secara hukum. Hal ini dibuktikan dari evaluasi yang diberikan oleh pengabdi pada tahap akhir pengabdian respon dari 30 responden. Kategori yang dapat dijabarkan dalam tulisan artikel jurnal ini adalah siswa dan siswi dapat:

a. Memahami mengenai pembinaan pengabdian seperti yang telah dijabarkan di atas, maka tim pengabdi telah memberikan pemahaman kepada responden, kemudia responden juga mudah mencerna informasi yang disampaikan

b. Pemberi tahuan terhadap golongan dari narkotika yang diatur di dalam Undang-Undang Narkotika

c. Lebih mengetahui, bahwasannya siapa saja yang memiliki izin dari pemerintah untuk memproduksi, menginpor dan mengekspor

d. Narkotika dan penyahgunaan narkotika berupa narkoba dapat dijatuhkan sanksi. 
Berdasarkan pemahaman politik siswa Madrasah Aliya Darul Ihsan Tanjung Sengkuang aturan yang dibuat oleh pemerintah seharusnya dijadikan acuan dalam menindak lanjuti permasalahan yang ada mengenai narkotika baik di: masyarakat, profesi, pekerja, mahasiswa dan di kalangan pelajar. Selain aturan seperti undang-undang, peraturan menteri juga ada surat-surat yang dikeluarkan oleh pemerintah sehingga hal tersebut terdapat didalamnya ada bagian dari politik terhadap penyusunan aturan, karena berdasarkan kewenangannya harus pejabat yang memiliki kewenangan yang dapat menyususn aturan tersebut. Namun dalam pelaksanaan dari aturan tersebut tetap dijalankan oleh BNN, Polisi, Jaksa dan Juga Hakim untuk menjatuhkan sanksi bagi pelaku yang melanggar aturan yang telah dibuat dan disahkan. Melalui dedikasi, materi yang diberikan terhubung pemahaman kepada peserta didik kelas XI dan XII Madrasah Aliya Darul Ihsan, antusiasnya siswa dan siswi tersebut dan sampai selesai. Berbagai isu terkait politik juga dibahas dalam diskusi dalam penerimaan materi narkotika. Menurut Wikler 1973 berdasarkan teorinya yaitu conditioning theory mengemukakan bahwa ketergantungan NAZA apabila ia terus-menerus diberikan barang haram tersebut (Madani Foundation (under construction), 2016). Oleh sebab itu, apabila siswa dan siswi dari sekolah madrasah ini dianggap paham dengan penyalahgunaan narkotika dimana penjabarannya secara rincitelah ditanyakan dalam tes yang diberikan oleh tim pengabdi pada akhir pengabdian. Selain itu siswa dan siswi juga diberitahukan serta dampak yang akan dirasakan apabila siswa dan siswi juga ikut-ikutan mengkosumsi narkotika.

Jika narkotika ini yang disalahgunakan oleh orang yang tidak bertanggyng jawab, kemudian tertangkap oleh polisi dan permasalahannya tersebut sampai dilanjutkan ke pengadilan maka dalam memutuskan hukuman hakim harus melihat kategori berikut:

Dalam mengadili kasus tersebut, hakim terikat pada Surat Edaran Mahkamah Agung No 4 Tahun 2010. Salah satunya memberikan batasan kadar narkoba yang didapati saat penangkapan. Di atas batas maksimal, maka dikenakan aturan hukum yang berlaku di UU Narkotika, bukan pecandu lagi. Berikut ini daftar batasannya:

a. sabu kurang dari 1 gram.

b. ekstasi kurang dari 2,4 gram atau sama dengan 8 butir.

c. kelompok Heroin kurang dari 1,8 gram.

d. kelompok Kokain kurang dari 1,8 gram.

e. kelompok Ganja kurang dari 5 gram.

f. daun Koka kurang dari 5 gram.

g. meskalin kurang dari 5 gram.

h. kelompok Psilosybin kurang dari 3 gram.

i. kelompok LSD (d-lysergic acid diethylamide) kurang dari 2 gram.

j. kelompok PCP (phencylidine) kurang dari 3 gram.

k. kelompok fentanil kurang dari $1 \mathrm{gram}$.

I. kelompok metadon kurang dari 0,5 gram.

m. kelompok morfin kurang dari 1,8 gram.

n. kelompok petidin kurang dari 0,96 gram.

o. kelompok kodein kurang dari 72 gram kelompok.

p. bufrenorfin kurang dari 32 mg (Oscar umbu siwa, 2020) 
2. Memberikan gambaran mengenai penyalahgunaan narkoba dan ancaman hukumannya.

Penyalagunaan narkotika tanpa adanya surat izin terlebih dahulu dari pemerintah sudah jelas melakukann pelanggaran aturan. UU Narkotika di keluarkan oleh DPR dan disahkan Presiden, dapat membantu Farmasi dalam membuat obat-obatan agar:

a. Ketersediaan narkotika untuk kepentingan pelayanan kesehatan dan/atau pengembangan ilmu pengetahuan dan teknologi.

b. Mencegah, melindungi, dan menyelamatkan bangsa Indonesia dari penyalahgunaan narkotika.

c. Memberantas peredaran gelap narkotika dan prekursor narkotika.

d. Menjamin pengaturan upaya rehabilitasi medis dan sosial bagi penyalah guna dan pecandu narkotika.

UU Narkotika ini telah diatur pula mengenai sanksi-sanksi pidana bagi pihak yang melanggar ketentuan di atas. Adapun sanksi yang terkait dengan UU Narkotika diatur mulai dari Pasal 111 s/d Pasal 148. Namun dalam praktik yang terjadi, pasal yang mendominasi, secara umum sering digunakan para penegak hukum (BNN, polisi, jaksa, hakim) adalah Pasal $111,112,113,114$ Jo 132. Dan pasal yang jarang dikenakan adalah Pasal 127.

\section{KESIMPULAN DAN SARAN}

1. Upaya yang dilakukan oleh Tim Pengabdi dalam pengabdian ini, agar dalam penanggapi perihal narkotika, siswa dan siswi Sekolah Madrasah Aliya Darul Ihsan jangan sampai terlibat dalam penyalahgunaan Narkotika, karena di dalam pengabdian ini sudah dijelaskan secara detail mengenai narkotika tersebut. Sebaiknya BNN juga sering turun ke sekolah-sekolah agar penerapan yang dilakukan oleh staff BNN dapat menceritakan secara detail kepada siswa dan siswi hal-hal mengenai narkotika yang terjadi di dalm praktek.

2. Memberikan gambaran mengenai penyalahgunaan narkoba dan ancaman hukumannya.

3. Tim pengabdi hanya menyarankan agar siswa dan siswi sebagai generasi muda dapat menjauhkan dirinya dari penyalahgunaan narkotika, sehingga masa depan siswa dan siswipun dapat berjalan dengan baik dan cita-cita yang diharapkan dapat diraih.

\section{DAFTAR PUSTAKA}

Https://www.hukumonline.com/pusatdata/detail/lt4af3b7f6cf607/nprt/1060/uu-no35-tahun-2009-narkotika. (2009, Oktober 12). Retrieved Mei 12, 2020, from Hukum Online: https://www.hukumonline.com/pusatdata/detail/t4af3b7f6cf607/nprt/1060/ uu-no-35-tahun-2009-narkotika

Admin Umum Sekda. $\quad$ (2019, September $\quad$ 5). https://umumsetda.bulelengkab.go.id/informasi/detail/artikel/bahayanarkoba-bagi-remaja-dan-pelajar-69. Retrieved Mei 11, 2021, from 
Pemerintah Kabupaten Buleleng Bagian Umum: https://umumsetda.bulelengkab.go.id/informasi/detail/artikel/bahayanarkoba-bagi-remaja-dan-pelajar-69

BNN, H. (2019, Februari 26). https://kalteng.bnn.go.id/jenis-jenis-narkoba/. Retrieved Mei 20, 2021, from Badan Narkotika Nasional Provinsi Kalimantan Tengah: https://kalteng.bnn.go.id/jenis-jenis-narkoba/

Kementerian PPN/Bapenas. (2016, September 5). http://www1.bappenas.go.id/id/berita-dan-siaran-pers/cross-checkpencapaian-pembangunan-nasional-penanganan-penyalahgunaannarkoba/. Retrieved Mei 11, 2020, from Kementerian PPN/Bappenas: http://www1.bappenas.go.id/id/berita-dan-siaran-pers/cross-checkpencapaian-pembangunan-nasional-penanganan-penyalahgunaannarkoba/

Madani Foundation (under construction). (2016, Januari 25). http://madanionline.org/beberapa-teori-ketagihan-dan-ketergantungannarkoba/. Retrieved Mei 11, 2021, from madanionline.org: http://madanionline.org/beberapa-teori-ketagihan-dan-ketergantungannarkoba/

Oscar umbu siwa . (2020, Mei 29). https://rean.bnn.go.id/aturan-pidana-ataurehabilitasi-bagi-penyalahguna-narkotika/. Retrieved Juni 2 , 2021, from Rean.ld: https://rean.bnn.go.id/aturan-pidana-atau-rehabilitasi-bagipenyalahguna-narkotika/ 